\title{
A Case Study on Research Postgraduate Students' Understanding of Academic Integrity at a Hong Kong University
}

\author{
Peter Lau* \\ Centre for the Enhancement of Teaching and Learning, The University of Hong Kong, Pok Fu Lam, Hong Kong
}

\section{OPEN ACCESS}

Edited by:

Eva Yee Wah Wong, Hong Kong Baptist University,

Hong Kong

Reviewed by:

Johanna Hall,

The Open University

(United Kingdom), United Kingdom

Ricky Lam,

Hong Kong Baptist University,

Hong Kong

*Correspondence:

Peter Lau

pfmlau@hku.hk

Specialty section:

This article was submitted to Digital Learning Innovations,

a section of the journal

Frontiers in Education

Received: 30 December 2020

Accepted: 17 March 2021

Published: 09 April 2021

Citation:

Lau P (2021) A Case Study on Research Postgraduate Students' Understanding of Academic Integrity

at a Hong Kong University.

Front. Educ. 6:647626.

doi: 10.3389/feduc.2021.647626
This case study aims to understand how research postgraduate (RPg) students at a Hong Kong university perceive academic integrity before and after participating in the Trail of Integrity and Ethics on the general issues of academic misconduct (TIE-General learning trail), which makes use of Augmented Reality (AR) technology and mobile application to help students acquire abstract concepts (Wong et al., 2018). A total of $33 \mathrm{RPg}$ students, who had completed the mandatory courses on research ethics and teaching skills, successfully completed the TIE-General learning trail. The participants were required to demonstrate their levels of understanding of academic integrity and ethics before and after going through the learning trail. Results of the thematic analysis on the participants' responses indicated that the RPg students were generally able to show some understanding of the six fundamental values of academic integrity defined by the International Center for Academic Integrity (ICAI), namely honesty, trust, fairness, respect, responsibility, and courage. Among these six values, the findings suggested that honesty and respect might be the most familiar values to the participants. However, the other four values seemed to be less familiar to them. On top of the above six values, empathy and mindfulness were considered as two other important attributes of academic integrity from the participants' perspectives. This article analyses the possible impacts of empathy and mindfulness on the academic integrity development of university students.

Keywords: academic integrity, research postgraduate, empathy, mindfulness, ICAl's values

\section{INTRODUCTION}

\section{Background}

Like their counterparts in other tertiary institutions across the globe, Research postgraduate (RPg) students at the University of Hong Kong (HKU) play various important roles in the University community. In addition to conducting primary research, RPg students often have to render support to different teaching and learning initiatives in the undergraduate programs by grading/marking assignments, invigilating at examinations, running tutorials, demonstrating in laboratories, facilitating other student learning activities in and outside the classroom. To pursue a successful career as qualified researchers or teachers after graduation, RPg students at HKU should not only acquire the necessary research and teaching skills, but also uphold their academic integrity, so that they could work both efficiently and ethically at the workplace. 


\section{Academic Integrity}

Academic integrity refers to an adherence to a collection of ethical values and behaviors demonstrated by individuals within the academic context (Young et al., 2018). It represents the foundational values and conducts in the daily practice of teaching and learning, research, and other pertinent services in academia (Macfarlane et al., 2014; Young et al., 2018). Thus, individuals should see integrity as a "personal choice" for a "consistent commitment" (Killinger, 2007, p. 12) to comply with the ethical and moral principles in different circumstances.

The word "integrity" borrows from integer, a Latin word, which derives meanings of entire, complete, pure, and honest (Kang, 2017). From a psychological point of view, Killinger (2007, p. 12) used wholeness, a psychological state of internal harmony, to describe consistent morality and essences of integrity. In academic context, integrity requires individuals to consistently internalize the sense of wholeness in academic services and works, regardless of circumstances. This expectation is applicable to all stakeholders, including students, teachers, researchers, and administrators, of any academic setting. Furthermore, having a sense of wholeness, an individual will be able to see the full picture of a situation. $\mathrm{He} / \mathrm{she}$ will consider all the variables or factors involved and make the right choice to contribute, establish and maintain the academic standard in his/her discipline (Killinger, 2007; Busch and Bilgin, 2014).

\section{Proposes of the Study}

This is a case study which aims to understand how RPg students at the HKU (one of the research-intense institutions in Hong Kong) perceive academic integrity before and after participating in the Trail of Integrity and Ethics on the general issue of academic misconducts (TIE-General). The virtual trail makes use of Augmented Reality (AR) technology and mobile app to help students acquire abstract concepts (Wong et al., 2018).

\section{LITERATURE REVIEW}

\section{Fundamental Values of Academic Integrity}

When the late Donald McCabe coined "academic integrity" in the 1990s, the term sounded vague due to its abstract and unclear boundaries. To conceptualize the meaning of academic integrity, the International Center for Academic Integrity (ICAI) defines academic integrity as a commitment to the five fundamental values for all academic activities even in the face of difficult situations, namely honesty, trust, fairness, respect, and responsibility (International Center for Academic Integrity [ICAI], 1999). These values guide all members in an academic community (including learners, teachers, researchers, administrators and sometimes alumni) to understand the principles and expectations of academic integrity.

According to the International Center for Academic Integrity [ICAI] (1999), the first value, honesty, is a prerequisite for seeking truth and knowledge. It is suggested that individuals who strongly adhere to facts and truth, as far as they know, are most likely to demonstrate honesty in their behavior. Once honesty is built in as a core value in an individual, it will help develop a climate of trust among the members of a community. The second value, trust, will facilitate free exchange of ideas and encourage further credible contributions grounded on the works of others (collaboration). It should be developed in reciprocal ways. When the individuals are willing to cooperate and share information, expectation of fairness and respect follows. Fairness, the third value emphasizes on the consistent and fair treatment to all members of a community when they interact with each other. It includes reasonable expectations and transparent procedures. Upholding fairness allows individuals to become role models who are respectable in an academic community. Fishman (2014) emphasizes that respect in academic communities is developed mutually, which means it requires individuals to "show respect for oneself as well as others" (p. 9). For oneself, it means to respond to the challenges from others with appreciation or to believe that it is an opportunity for improvements. For others, it means to recognize and value diversity. Lastly, when the above four values are cultivated in an academic community where all members are both respectful and respectable, a collective responsibility will be developed. The fifth value, responsibility, refers to the personal active endeavors to safeguard integrity in all academic activities and procedures (including scholarship of teaching and learning). It involves serving as good examples to stand up against academic misconducts, and to refrain from violating any ethical and academic principles.

Failure to embrace these five values will put one's academic career in peril as others would doubt the credibility of his/her works. However, it is easier said than done. A few studies (for example, Carrell et al., 2008; Fernandez, 2019; Moldes et al., 2019) found that peer pressure or influence is one of the most tempting factors leading to academic misconducts, such as plagiarism, cheating in examination, etc., even though some might not have the intention to cheat. Research studies repeatedly found that a student who found a classmate cheating would struggle to stand up to them or report the misconducts to teachers since he/she was afraid of ending their friendships. Carrell et al. (2008, p. 173) also reported an astonishing result that "with one additional cheater, it drives approximately 0.67 to 0.75 additional students to do cheating." Based on their findings, they approximated that the social multiplier for academic cheating could be as high as three.

In view of the significant impact of peer pressure on one's academic integrity, the ICAI introduced courage as an additional element to the above five values. The second edition of Fundamental Values of Academic Integrity was published in 2014 (Fishman, 2014). This additional element conveys a clear message that we should go beyond "simply believing in the fundamental values" (p. 13). Rather, courage represents our determination and strategies to put values into actions and overcome any fear.

\section{Approaches to Develop Academic Integrity at HKU}

Like other institutions in the world, the HKU established a few typical measures to facilitate its staff and students to develop academic integrity. One of the measures adopts a 
disciplinary approach by rolling out pertinent rules and policies (such as Plagiarism, Photocopying of Printed Works, Privacy Policy Statement, Policy on Research Integrity, etc.) to regulate academic behaviors/procedures. This approach emphasizes on the fact that an individual who violates any policies on academic integrity should be liable to penalties or other negative consequences, such as a fail grade and disqualification. To a certain extent, this approach works well to discourage students from cheating in tests/examinations, committing plagiarism in coursework, and falsifying data in research (behavioral change). However, Young et al. (2018) argued that in this approach, students tend to pay much attention to avoid adverse consequences, but not to the underlying values and morality of academic honesty. To make sense of the values, there is a need to create opportunities for students to practice on the values, rather than hiding from the watching eyes.

On the other hand, an educational approach is also adopted at HKU. Rather than penalizing an individual for ethics violation, this approach focuses on preventive measures to educate students on how to develop understanding of academic integrity through participation in certain mandatory programs, such as induction seminars and workshops. To further encourage self-learning on academic integrity, all postgraduate students are required to complete the online course of Responsible Conduct of Research under the Collaborative Institutional Training Initiative (CITI) program. This program consists of several discipline specific course web-based courses. Course participants could choose from the five existing research areas, including clinical research, social/behavioral research, science research, humanities, and engineer and architects. The online course covers nine topics of study such as research misconduct, data management, authorship, conflicts of interest, etc. To successfully complete this course, students are required to obtain a score of at least $80 \%$ in the quizzes (multiple-choice questions) of each topic. After meeting the above requirements, students are required to sign and submit a declaration form to their affiliated faculty office, to indicate that they understand and agree to follow the University's academic regulations and policies. This educational approach provided students with an opportunity to clarify the rationale of the values, regulations, and policies. Students will become more sensitive to the potential risks and learn the necessary knowledge and skills to avoid any misconducts in their academic activities. However, there is one major limitation in this approach. Only knowing the correct answers to questions or ethical values will not lead a person to act ethically at all times. There could be some cognitive changes after taking those online courses but still no guarantee for any attitudinal or affective change.

Braunschweiger and Goodman (2007) analyzed the CITI program evaluation data when it reached 600,000 participants from more than 715 institutions in 2007. They found that the program generally allowed learners to respond to the materials in ways that "transcend mere compliance" (p. 861), because the course design is based on the framework in which critical thinking is a fundamental skill to moral reasoning. However, they argued that "the current thrust toward the (online) training is misguided" (p. 863), because the CITI program had been considered as a tool to train the skills (cognitive changes), rather than to develop learners' conceptual foundations to support their briefs and practices (attitudinal change).

\section{Proactive Approach to Nurture Students' Integrity in Higher Education}

Targeting on the attitudinal or affective change, Tan and So (2015); Bealle (2017), and Young et al. (2018) argued for a more proactive approach to put students in various real-life scenarios or ethical dilemmas in which they have to make ethical decisions, argue for their choices, and reflect on the experience. Rather than figuring out the "correct" or "model" answers in the scenarios, this approach focuses on the real/virtual experience reinforcing students' abilities to interpret situations, analyze any possible consequences, and justify their choices (for practical solutions rather than the ideal options). Students also have the opportunities to reflect on their experience, as a second-time exposure to the same situation, organize and consolidate their thoughts to better prepare themselves for any similar encounters in the future. To ensure an effective learning process, O'Connell (2016) suggested that teachers should guide students to discuss those scenarios with their peers step-by-step.

Furthermore, numerous interesting examples (by making use of positive peer influence) are suggested for this developmental approach around the world. For example, in an Australian university, Deborah Richards et al. (2016) piloted a project with an idea of using student ambassadors to promote academic integrity; in a Canadian university, Lucia Zivcakova et al. (2012) studied the impact of residential student leaders on academic integrity of others. The above studies tried to reinforce the fact that peers play crucial roles in influencing students' perceptions of academic dishonesty (McCabe and Trevino, 1993).

\section{Pedagogical Innovation: Learning Trails of Integrity and Ethics}

Learning Trails of Integrity and Ethics are thoughtful mobile learning activities developed in a government-fund teaching and learning research project led by Hong Kong Baptist University, which collaborated with The Chinese University of Hong Kong (CUHK), The Education University of Hong Kong (EdUHK) and The Hong Kong Polytechnic University (PolyU). In consideration of the increasing difficulties of observing academic integrity in curriculum with the advent of informative technology (IT), the project aims to explore various ways to make use of Augmented Reality (AR) technology to combat the issue of academic misconducts worsened by IT advancements (Wong et al., 2018). Eleven AR learning trails were developed with various focuses on the general concepts of academic integrity (the TIE-General version focuses on data falsification, citation, and proper use of library resources), ethics education for professional disciplines (such as humanities, science, business, language, social sciences, etc.), and student personal growth programs (such as service-learning, residential life tutor training, etc.). See a few screenshots of the TIE-General learning trail in Figure 1.

In general, the pedagogical design elements include a repository of relevant scenarios (putting student in real-life situations), bite size teaching materials (displaying key concepts 

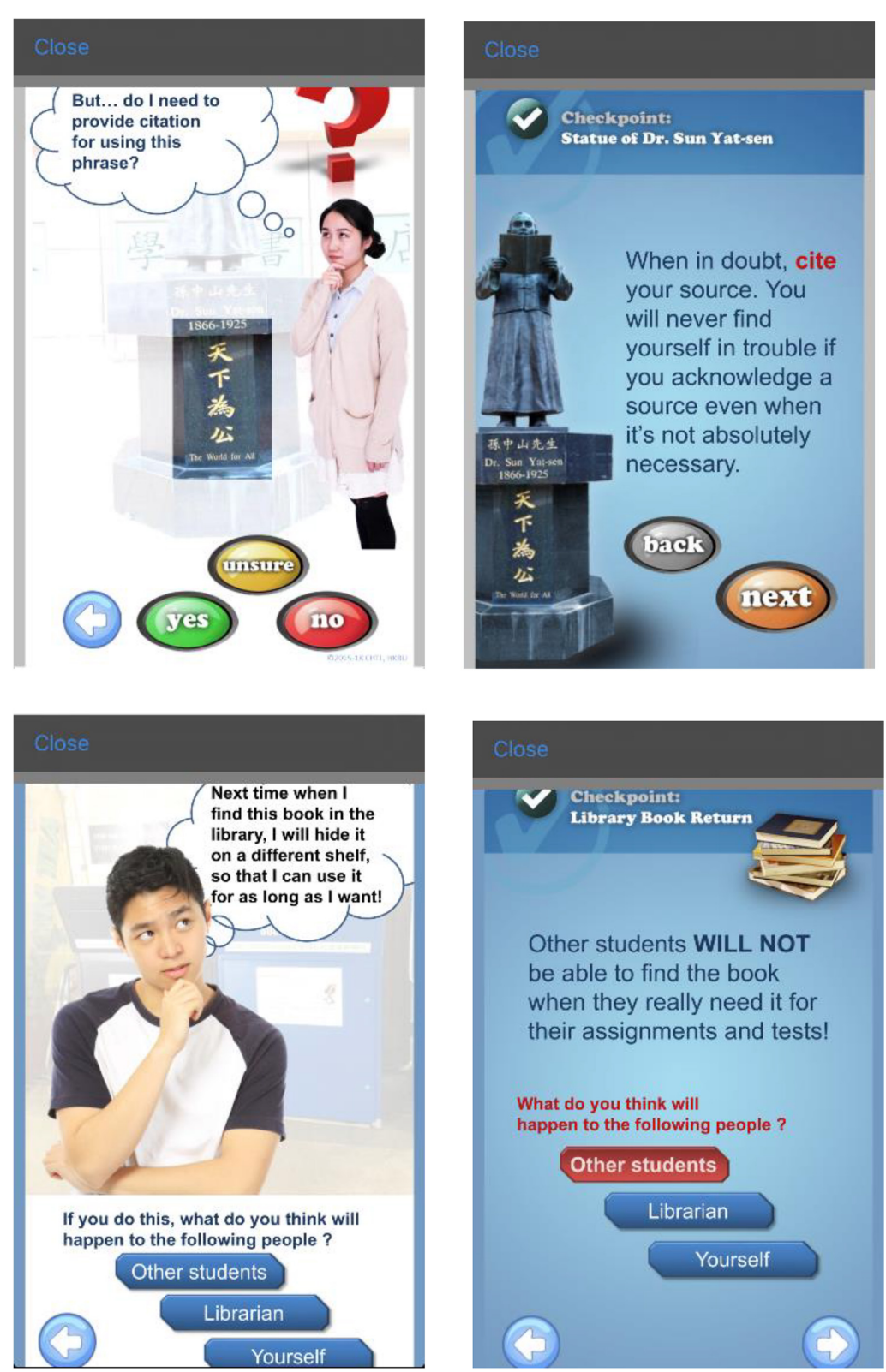

FIGURE 1 | Screenshots of the TIE-general learning trail (Scenarios of Citation and Library Resources).

in short videos), interactive problem-solving process (giving explicit feedback on players' choices), pre-trail surveys (triggering mental preparation), and post-activity reflection (reinforcing learning). Since the first launch of the AR learning trail in 2014, this pedagogical design has been adopted in different academic programs and co-curricular activities of the four participating institutions. Participation in the trials has become a graduation requirement for both undergraduate and postgraduate students in these universities. As of 2020, over 9,000 students have participated in the learning trails on their own campuses.

It is suggested that the AR learning trail represents a typical example of developmental approach to nurture and develop students' academic integrity. This case study aims to understand how the HKU RPg students perceive academic integrity. Thus, the TIE-General, one of the learning trail versions that focuses on the general concepts, was chosen as the learning activity in this study.

\section{METHOD AND METHODOLOGY}

\section{Method Approach, Sampling and Methods}

This is a case study, which adopts a qualitative approach (Merriam, 1998). It aims to understand how the HKU RPg students perceive academic integrity against the six fundamental 
values put forward by ICAI. It targeted to study the RPg students who (1) finished the University's mandatory research ethics course, (2) completed the University's mandatory teaching training course, Certificate in Teaching and Learning in Higher Education course (CTLHE course), between February and May 2020, and (3) enrolled to a $\mathrm{PhD} / \mathrm{MPhil}$ program for at least one semester. The above selective criteria were to ensure that all the participants are familiar with ethics in research and teaching duties, as well as the relevant policies adopted by the University.

Invitation emails indicating these three requirements were sent to all the CTLHE course participants who completed the course in the above period. A total of 41 students agreed to participate in the study and 33 of them completed all the three checkpoints (for data falsification, citation, and proper use of library resources) in the TIE-General learning trail and submitted both pre-trail survey and post-activity survey of reflection. Finally, 33 valid matched samples were collected. There were 14 males (42.4\%) and 19 females (57.6\%) in the group of participants. The 33 samples indicated their study majors spread across seven disciplines, including Architecture (1), Arts (8), Education (3), Engineering (4), Science (3), Social Sciences (5), Medicine (9). The samples skewed a bit to the disciplines of Arts and Medicine.

In view of the needs of social distancing during the COVID19 pandemic in 2020, the University decided to cancel all unnecessary student activities on campus and replace all face-toface teaching and learning activities with online teaching. Thus, the "checkpoints visiting" part of the TIE-General learning trail activity was canceled. Rather than visiting the checkpoints with peers, participants could join the learning trail over the internet at their own pace. In the original design of the learning trail, the scenario of ethical dilemmas at each checkpoint is triggered by the GPS locator of the mobile devices of the participants when they are only meters away from the checkpoints. However, in the modified virtual learning trail of this study, QR codes were used to trigger the specific scenarios. This change might have minor impacts on the user experience, but the deliveries of information and scenarios were the same.

Once the students confirmed their participation, they would receive a set of instructions including guidelines to download and operate the mobile application. They were also assigned with a unique set of login ID and password which allowed them to access the mobile application. Students were allowed to complete this 30 -min virtual learning trial by themselves within 2 weeks' time.

\section{Data Collections and Analysis}

At the beginning of the learning trail, participants had to complete a pre-trail survey in which they needed to explain academic integrity according to their understanding with about 100 words. After that, in each of the three following scenarios, participants would interact with the mobile application and receive bite-size videos or reading materials. Participants could go back anytime for changing their choices and study other possible consequences and explanations from the application. After completing all the three scenarios, participants would receive three checkpoint codes. When a declaration of "I must not cheat" came up by putting those codes in correct order participants could then unlock the final challenge of the Trail. The final task included six survey questions on the user experience of the App (see Table 1) and post-trail reflection, which requires participants to explain their refreshed and enhanced understanding of academic integrity in 100 words.

The qualitative data collected before and after participating in the virtual learning trail was analyzed by a flexible thematic analysis method, which employs a hybrid approach of two main methods of reasoning: a top-down deductive process and a bottom-up inductive process (Swain, 2018). In this study, the top-down deductive process produced a set of priori codes with reference to the six fundamental values of academic integrity from the literature. The bottom-up inductive process resulted in two posteriori codes (empathy and mindfulness) from an examination of the students' responses. The results of descriptive statistics were summarized in Figure 2. It is believed that those posteriori codes would be helpful for educators or researchers to explore, expand or elaborate the ICAI's fundamental values from RPg student's perspective.

\section{RESULTS AND DISCUSSION}

\section{Overall Comparison of Individual Student's Responses Before and After Learning Trail}

Based on the descriptive statistics results (Figure 2), among the 33 participants, it was found that 25 (75\%) and 19 (57\%) individual responses mentioned the values of honesty and respect respectively in the pre-trail survey, while 28 (84\%) and 25 (75\%) individual responses mentioned these two values in the post-trail survey. It seemed to suggest that students' understanding of these two values (honesty and respect) might be strengthened in the learning trail. However, regarding the other four values (trust, fairness, responsibility, and courage), in both pre-trail survey and post-activity reflection, the number of students' responses remained low and a drop is identified. This might be due to the limited coverage of the three scenarios in the learning trail. The topics adopted in the scenarios (data falsification, citation, and proper use of library resources) seemed to be apparently relevant to honesty and respect than the other four ICAI's fundamental values. These scenarios seemed to create a condition driving the participants to re-construct their understanding based on the two apparent values. For instance, increasing student responses regarding the theme of honesty associated with the data falsification scenario. To name a few:

\footnotetext{
"No fabrication..."

"Do not change data for the perfect results."

"Do not try to manipulate data."

"... academic integrity is to avoid falsification. .."

“... stating data and methods honestly and not intentionally ignoring data in order to deliver expected research results."

"... data must not be selectively skewed for the sake of one's personal academic benefit (i.e., must be given proper variables to prevent fabrication and falsification)."
} 
TABLE 1 | Post-trail survey results.

\begin{tabular}{|c|c|c|c|c|c|c|}
\hline Post-trail survey questions & SA & A & $\mathbf{N}$ & D & SD & Mean \\
\hline 1. I find the AR Trails App easy to use. & 11 & 21 & 1 & 0 & 0 & 4.3 \\
\hline 2. My interaction with the AR Trails App is clear and understandable. & 10 & 22 & 0 & 1 & 0 & 4.2 \\
\hline 3. The AR Trails App makes learning academic integrity and ethics more interesting. & 12 & 18 & 3 & 0 & 0 & 4.3 \\
\hline 4. Working with the AR Trails App is fun. & 6 & 17 & 9 & 1 & 0 & 3.8 \\
\hline 5. The WiFi connection is stable. & 17 & 13 & 2 & 1 & 0 & 4.4 \\
\hline 6. My overall usage experience with this learning trail is good. & 9 & 21 & 3 & 0 & 0 & 4.2 \\
\hline
\end{tabular}

SA, Strongly Agree (5); A, Agree (4); N, Neutral (3); D, Disagree (2); SD, Strongly Disagree (1).

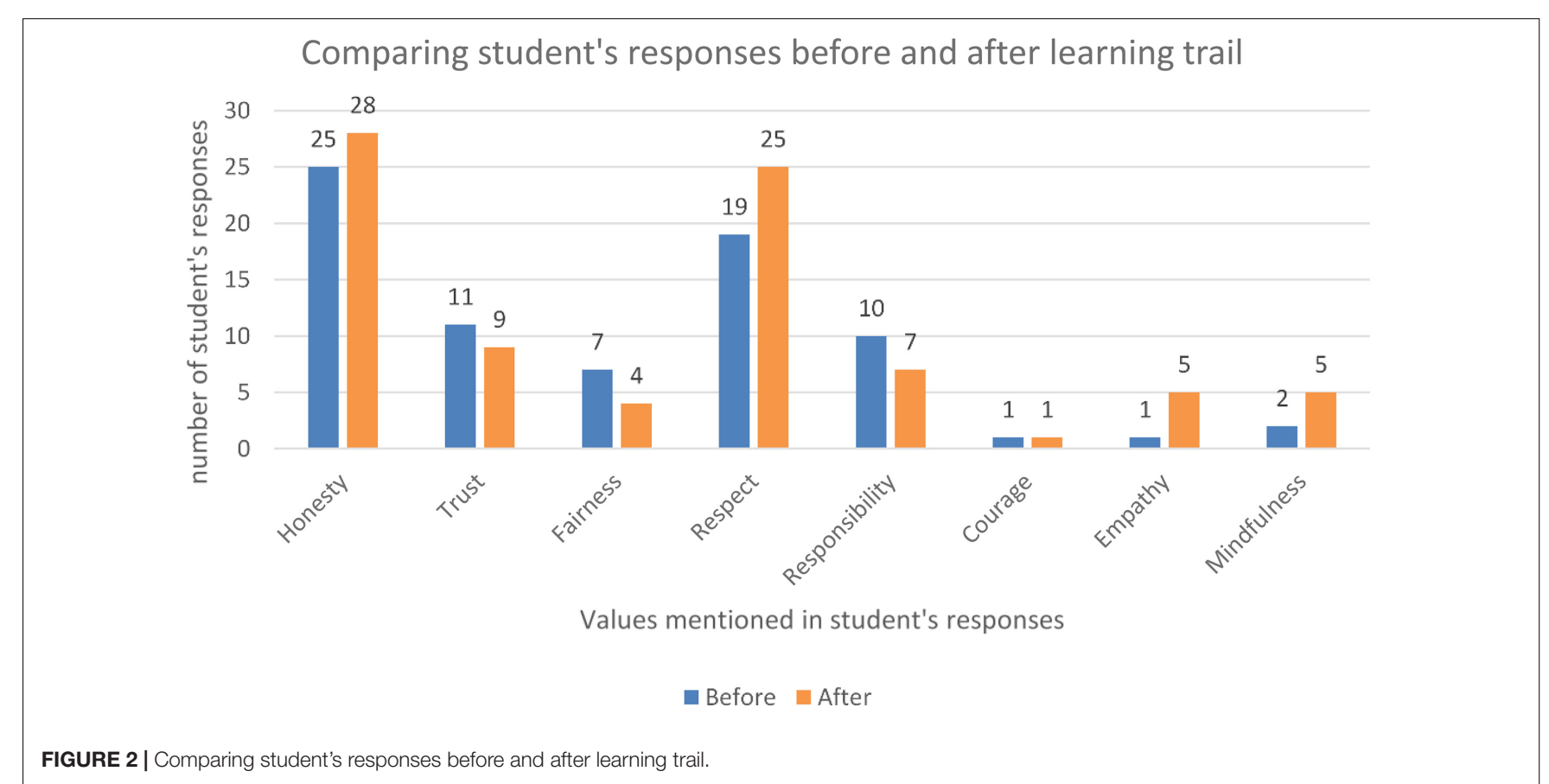

Whereas, most of the student responses regarding the theme of responsibility extensively associated with the citation scenario. See below selected examples:

“... acknowledge the contributions of other people."

“... recognize others' works in their research."

"... provide credits to third party."

"... cite the proper sources."

There might be a limitation in the scenario design. To minimize the skewed results, it is suggested to incorporate all the six values into the scenarios in a more balanced way, for example, developing a few other scenarios for the TIE-General. Possible scenarios include grading student/peer assignments (fairness), academic collaboration (trust), following ethical procedures (responsibility), reporting peer cheating (courage), etc. That might help to raise the awareness of the six ICAI's values to the participants.

Though Figure 2 shows a drop in mentions of the other four values (trust, fairness, responsibility and courage), since the sample size was relatively small $(n=33)$ and the length of writing was limited to 100 words, there is insufficient evidence to conclude whether any significant decrease exists. However, by increasing the sample size $(n=200)$, it is possible to draw a meaningful conclusion with valid statistical test results then. Besides, increasing the length of writing (e.g., 3-500 words) would also help to enrich the qualitative data.

\section{Thematic Analysis - Students' Perception Before Learning Trail}

The results indicated that the overall pre-trail and posttrail student responses covered the ICAI's six fundamental values. In addition to these six values, two other meaningful attributes were identified from the student responses. Before participating in the learning trail, one RPg student used "empathy" to illustrate his/her understanding of academic integrity.

That student perceived "empathy" as the attitude and willingness to put oneself in a situation: how bad is the feeling if someone cheats on me or steals ideas from my works. It is different from the original six fundamental values which mostly emphasize on the positive consequence of upholding academic integrity. The sense of empathy in this 
context highlights the imaginary experience of suffering, and the unpleasant consequence on others (the victims). In other words, it goes in line with the following traditional Confucius thought:

"Do not do to others what you do not want to be done to you." - from Lunyu (Analects of Confucius)

It is believed that this new thought helps remind students to think for others, e.g., to imagine the negative consequences that might bring to others, rather than considering their own benefits.

On the other hand, two RPg students also indicated in their pre-trail surveys that "self-awareness" and "conscious(ness)" represented one's self-regulating abilities in a new academic environment without any surveillance from others. The participants tried to relate to the emerging challenges in online assessment (examination) and the extensive use of technologies in academic works during the pandemic in 2020. This finding suggested that an academic should always stay alert in the ever-changing environment where new temptations turn up from time to time. Mindfulness (or being mindful in this context) enable the students to suspend any emotional reactions to pause and rethink from a new angle when they find themselves in difficult situations of making ethical decisions. This is another important attribute that students should develop at the early stage of their academic careers.

From the above findings, two new attributes (empathy and mindfulness) were identified apart from the ICAI's six fundamental values.

\section{Thematic Analysis - Students' Perception After Learning Trail}

In the post-trail reflection, apart from the six fundamental values, increasing responses to the others (empathy and mindfulness) were observed. There was an increase from 3 (pre) to 10 responses (post) as shown in Figure 2. More students related their perceptions of academic integrity to these additional attributes. A few students' responses highlighted the needs to take the cultural/educational background of the target audience (such as readers of journal articles) into consideration. This echoed the theme of empathy as participants elaborated on the need for proper citation and references. Besides, some students' responses also revealed the fact of increasing temptations of ethics violation on campus during the current pandemic. While encountering uncertainties (such as noticing peer cheating or misconducts) and other new situations, they identified the need to consult supervisors or seniors if they had no experience or guidelines to follow in handling those situations. These views extended elaboration to mindfulness. On one hand, the attribute of mindfulness is developed at an individual level which means that a person stays alert to uncertainties in his/her daily work. On the other hand, it induces an individual to engage in discussions with others on those uncertain issues for solutions. Such active engagement among the individuals could help promote mindfulness in the learning community.

\section{Results of the Post-survey on User Experience}

According to the results in Table 1, the participants, in general, agreed that the virtual learning trail made learning academic integrity and ethics more interesting (mean score: 4.3) and that working with the app is fun (mean score: 3.8). They also found the app easy to use (mean score: 4.3) and the instruction was clear and understandable (mean score: 4.2 ). The learning trail was different from the traditional ethics education (disciplinary and educational approaches), because participants could experience and react to different scenarios enhanced by the AR technology. The trail was well received by the participants because of the flexible blended learning experience brought to them during the activity.

\section{Existing Views on Empathy and Mindfulness in Academic Integrity From the Literature}

In this study, some participants argued for the value of empathy in academic integrity because they see the need to be considerate to others. For example, one decides to add a citation or footnote not just for acknowledging others' contribution to the ideas, but also for offering the sources of specific cultural knowledge to the readers having different cultural background so that they could identify the sources easily for a better reading experience. While the participants hold positive views on empathy in academic integrity, they seemed to overlook the fact that empathy could impede ethical decision making. In fact, there is a major concern on the value of empathy in making ethical decisions or moral judgments (Coplan and Glodie, 2012).

According to Decety's (2016) definition (2016), empathy represents one's capability to interpret others' emotional states. It is characterized as a "vicarious emotion" that a person experiences to reflect on others' emotion (Prinz, 2011). However, it was found that the study on empathy in academic integrity development context was relatively limited. Thus, I chose to draw some literatures from the field of moral judgment or justice to discuss here. In the article, Against Empathy, Prinz (2011) explains the dark side of empathy in moral judgment, such as the "prone to bias" (p. 214), "precondition for approbation" (p. 216), and "easily manipulated" (p. 227), etc., which could lead to unethical and harmful consequences. Prinz (2012) also argued that empathy is potentially an impediment to one's motivation of making ethical decisions or moral judgments, one should not even try to cultivate empathy-based morality. In view of this argument, Hoffman (2012), one of the scholars defending the importance of empathy in moral thought, also admitted that it is necessary to clarify the limits of empathy, even though it has contributed importantly to the justice in the US law system.

While there are critiques of the value of empathy in ethical decision-making and morality, there are several studies supporting the needs to address mindfulness in the process of academic integrity development.

The term mindfulness, originated from the Pali language word sati which means to remember as a way of consciousness, represents the "present of mind" (Brown et al., 2007, p. 212). 
Brown and colleagues have also defined mindfulness as a "receptive attention to and awareness of present events and experience” (p. 212). In their study, Ruedy and Schweitzer (2010) explored how mindfulness influences students' ethical decisionmaking and recognized that students with higher levels of mindfulness (self-reported) tended to act ethically, embrace the values, and uphold the professional standards. Recently, Culiberg and Miheličss (2020) structural equation modeling (SEM) study on the impact of mindfulness on students' response to peers' academic dishonesty also contributes a clear picture of how mindfulness influences students' ethical decisions in a university. Many studies seemed to support the needs to strengthen students' mindfulness in developing students' academic integrity, because the causes of academic misconducts, such as self-serving bias (Epley and Caruso, 2004), are "exacerbated by a lack of attention and awareness" (Ruedy and Schweitzer, 2010, p. 73).

\section{IMPLICATIONS ON TEACHING OR PEDAGOGY}

Assigning pre-class readings (e.g., assessment policies and cases) and then follow-up with in-class discussion on various scenarios is a very common practice to deliver knowledge and values of academic integrity. This pedagogy has been used in my course for a while, but I have no idea how good or bad did the students engage with the reading materials. However, in this new implementation (using the AR technology), in addition to the above-mentioned user experience survey results, the system could also generate learning analytics reports which allow me to know how long they have spent on reading materials, the tasks or questions, as well as any common misconception or mistake. I could then plan to improve the course design accordingly.

On the other hand, the mobile app will provide immediate feedback or explanation to the learners if they choose the wrong answers. It also saves my time to take an overview of the class performance.

\section{LIMITATIONS}

\section{Sampling and Methods}

The scale of this case study is relatively small. Due to the restricted sampling requirements (see the sampling section), there were only 33 participants who successfully completed the learning trail and submitted all surveys. Higher reliability could be maintained if hundreds of participants (for example 200) are involved. The participants' responses in the surveys were quite brief as they were required to write 100 words to describe their understanding of academic integrity. The depth and richness of data could be improved if participants could write a short/mini-essay, around 300-500 words or within one A4 page.

The findings in this study were mainly based on student surveys. Due to the suspension of face-to-face classes, focus group discussions and interviews were not implemented. For improving reliability and data triangulation, it is suggested to arrange online focus group discussions in addition to the student surveys to understand their personal views and learning experience in the future.

\section{Implementation}

In view of the social distancing requirement in the COVID-19 pandemic, all the face-to-face student activities on campus were replaced with online and virtual ones. The "checkpoints visiting" of the TIE-General learning trail activity was also canceled. Although a QR code scanner was used to replace the GPS locator technology to trigger scenarios, the teaching materials delivery remains the same. There is a major difference in user experience between the original and virtual learning trails. The participants in the virtual trail could join the activity individually at their own pace within two weeks. In the original learning trail, participants will join it with peers at the same time, so they could discuss the materials with each other when they move from one checkpoint to another (around $5 \mathrm{~min}$ ). Such informal social learning opportunity is missing in the virtual version. Though such peer interaction is very informal, it somehow creates a positive condition to engage participants in discussion and the tasks in the original version. It might be very helpful if a synchronous peer discussion could be arranged for the virtual learning trail.

\section{Scenarios Design}

As discussed in earlier sections, the three scenarios of the TIEGeneral learning trail mainly aligned with the honesty and respect values. That might create a condition to drive the participants to re-construct their understanding based on the two values. To raise the awareness of the six ICAI's values, it is suggested to find a balanced way to incorporate all the values into the scenarios. Possible additional scenarios include grading student/peer assignments (fairness), academic collaboration (trust), following ethical procedures (responsibility), reporting peer cheating (courage), etc.

\section{CONCLUSION}

The participants (33 RPg students) in this case study found the AR learning trial easy to use and believed that it made learning academic integrity more interesting. According to their responses in the pre-trial survey and post-trial reflection, participants were generally able to identify the ICAI's six fundamental values, namely honesty, trust, fairness, respect, responsibility, and courage. Among these six values, the findings suggested that honesty and respect might be the values most familiar to the participants prior to joining the learning trail. Their understanding of these two values seemed to be strengthened after the activity. However, the other four values seemed to be less familiar to the participants even though they indicated that they understood the University's policies on academic integrity and have completed the mandatory courses on research ethics and basic teaching. Their understanding of these four values remained at a low level after going through the learning trial. It is suggested to develop more scenarios so as to expand the coverage of the learning trail on the six fundamental values and explore alternative means 
to facilitate effective peer discussion in the trail. Though the participants had experienced the scenarios, the learning trail was held as an individual activity eventually, since the mandatory measure of social distancing on campus during the pandemic had prohibited "the walk with peers" and any synchronous discussion in person.

On top of the six values, empathy and mindfulness were identified as the two other important values to develop academic integrity from participants' perspectives. Increasing responses on these two values were identified in the post-trail reflection. Though some participants might perceive empathy as an important attribute in developing academic integrity, there is no direct evidence from literature to support this saying. Rather, to borrow insights from other relevant studies on ethical decision making and morality, there is a dark side of empathy that could lead individuals to make unethical decisions when encountering uncertainties (Prinz, 2011, 2012), such as observing peer cheating in an examination. Educators should pay extra attention to this students' perception of empathy to avoid any misinterpretation. As suggested, there is a need to delineate the limits of empathy in personal decision-making for upholding academic integrity. To prevent students from falling into the traps induced by empathic emotions, a well-developed mindfulness might help

\section{REFERENCES}

Bealle, P. (2017). Community college academic integrity lessons that put research into practice. Theory Pract. 56, 144-155. doi: 10.1080/00405841.2017.128 3573

Braunschweiger, P., and Goodman, K. W. (2007). The CITI program: an international online resource for education in human subjects protection and the responsible conduct of research. Acad. Med. 82, 861-864. doi: 10.1097/acm. 0b013e31812f7770

Brown, K. W., Ryan, R. M., and Creswell, J. D. (2007). Mindfulness: theoretical foundations and evidence for its salutary effects. Psychol. Inq. 18, 211-237. doi: 10.1080/10478400701598298

Busch, P., and Bilgin, A. (2014). Student and staff understanding and reaction: academic integrity in an Australian university. J. Acad. Ethics 12, 227-243. doi: 10.1007/s10805-014-9214-2

Carrell, S. E., Malmstrom, F. V., and West, J. E. (2008). Peer effects in academic cheating. J. Hum. Resour. 43, 173-207. doi: 10.3368/jhr.43. 1.173

Coplan, A., and Glodie, P. (2012). Empathy: Philosophical and Psychological Perspectives. Oxford: Oxford Scholarship Online, doi: 10.1093/acprof:oso/ 9780199539956.001 .0001

Culiberg, B., and Mihelič, K. K. (2020). The impact of mindfulness and perceived importance of peer reporting on students' response to peers' academic dishonesty. Ethics Behav. 30, 385-399. doi: 10.1080/10508422.2019.16 28644

Decety, J. (2016). Is empathy necessary for morality? Int. J. Psychophysiol. 108:24. doi: 10.1016/j.ijpsycho.2016.07.078

Epley, N., and Caruso, E. (2004). Egocentric ethics. Soc. Justice Res. 17, 171-187. doi: 10.1023/b:sore.0000027408.72713.45

Fernandez, J. (2019). The Effects of Parental Pressure and Peer Pressure on the Academic Dishonesty of College Students During Examinations (term paper. Berlin: ResearchGate.

Fishman, T. (2014). The Fundamental Values of Academic Integrity, 2nd Edn. Clemson, SC: Clemson University.

Hoffman, M. L. (2012). "Empathy, justice, and the law," in Empathy: Philosophical and Psychological Perspectives, eds A. Coplan and P. Glodie (Oxford: Oxford Scholarship Online), doi: 10.1093/acprof:oso/9780199539956.003. 0015 them to overcome the struggles and make an informed decision in uncertain circumstances.

\section{DATA AVAILABILITY STATEMENT}

The original contributions presented in the study are included in the article/supplementary material, further inquiries can be directed to the corresponding author/s.

\section{ETHICS STATEMENT}

The studies involving human participants were reviewed and approved by Human Research Ethics Committee, The University of Hong Kong. The patients/participants provided their written informed consent to participate in this study.

\section{AUTHOR CONTRIBUTIONS}

The author confirms being the sole contributor of this work and has approved it for publication.

International Center for Academic Integrity [ICAI] (1999). Fundamental Values of Academic Integrity. Albany NY: International Center for Academic Integrity.

Kang, S. (2017). The True Meaning of Integrity. New York, NY: Huffpost.

Killinger, B. (2007). Integrity: Doing the Right Thing for the Right Reason. London: McGill-Queen's University Press.

Macfarlane, B., Zhang, J., and Pun, A. (2014). Academic integrity: a review of the literature. Stud. Higher Educ. 39, 339-358.

McCabe, D. L., and Trevino, L. K. (1993). Academic dishonesty. J. Higher Educ. 64, 522-538. doi: 10.1080/00221546.1993.11778446

Merriam, S. (1998). Qualitative Research and Case Study Applications in Education. San Francisco, CA: Jossey-Bass.

Moldes, V. M., Biton, C. L. L., Gonzaga, D. J., and Moneva, J. C. (2019). Students, peer pressure and their academic performance in school. Int. J. Sci. Res. Publ. 9, 300-312.

O'Connell, J. (2016). Networked participatory online learning design and challenges for academic integrity in higher education. Int. J. Educ. Integ. 12, 1-15. doi: 10.1016/j.iheduc.2015.04.007

Prinz, J. (2011). Against empathy. South. J. Philos. 49, 214-233. doi: 10.1111/j. 2041-6962.2011.00069.x

Prinz, J. J. (2012). “Is empathy necessary for morality?," in Empathy: Philosophical and Psychological Perspectives, eds A. Coplan and P. Glodie (Oxford: Oxford Scholarship Online), doi: 10.1093/acprof:oso/9780199539956.003. 0014

Richards, D., Saddiqui, S., White, F., McGuigan, N., and Homewood, J. (2016). A theory of change for student-led academic integrity. Qual. Higher Educ. 22, 242-259. doi: 10.1080/13538322.2016.126 5849

Ruedy, N. E., and Schweitzer, M. E. (2010). In the moment: the effect of mindfulness on ethical decision making. J. Bus. Ethics 95, 73-87. doi: 10.1007/ s10551-011-0796-y

Swain, J. (2018). A Hybrid Approach to Thematic Analysis in Qualitative Research: Using a Practical Example. Thousand Oaks, CA: SAGE Research Methods Cases, doi: 10.4135/9781526435477

Tan, E., and So, H. J. (2015). Rethinking the impact of activity design on a mobile learning trail: The missing dimension of the physical affordances. IEEE Trans. Learn. Technol. 8, 98-110. doi: 10.1109/tlt.2014.23 76951 
Wong, E., Law, L., Kwong, T., and Pegrum, M. (2018). Experiences from augmented reality trails of integrity and ethics to help students learn abstract concepts. J. Excel. Coll. Teach. 29, 37-52.

Young, R. L., Miller, G. N. S., and Barnhardt, C. L. (2018). From policies to principles: The effects of campus climate on academic integrity, a mixed methods study. J. Acad. Ethics 16, 1-17. doi: 10.1007/s10805-017-9297-7

Zivcakova, L., Wood, E., Forsyth, G., Dhillon, N., Ball, D., Corolis, B., et al. (2012). Examining the impact of dons providing peer instruction for academic integrity: dons' and students' perspectives. J. Acad. Ethics 10, 137-150. doi: 10.1007/s10805-012-9153-8
Conflict of Interest: The author declares that the research was conducted in the absence of any commercial or financial relationships that could be construed as a potential conflict of interest.

Copyright (c) 2021 Lau. This is an open-access article distributed under the terms of the Creative Commons Attribution License (CC BY). The use, distribution or reproduction in other forums is permitted, provided the original author(s) and the copyright owner(s) are credited and that the original publication in this journal is cited, in accordance with accepted academic practice. No use, distribution or reproduction is permitted which does not comply with these terms. 